\title{
SUSPEITOS? NARRATIVAS E EXPECTATIVAS DE JOVENS NEGROS E NEGRAS E POLICIAIS MILITARES SOBRE A ABORDAGEM POLICIAL E A DISCRIMINAÇÃO RACIAL EM BRASÍLIA, SALVADOR E CURITIBA
}

Evandro Piza Duarte ${ }^{1}$

Laís da Silva Avelar ${ }^{2}$

Rafael de Deus Garcia ${ }^{3}$

\section{Resumo}

No contexto de discussão das altas taxas de homicídios de jovens negros, o artigo explora a dimensão da violência racial praticada no âmbito das instituições de segurança e seus efeitos sobre os alvos dessas instituições. Discutemse as narrativas, obtidas por meio de grupos focais, de policiais militares e de jovens negros em três cidades brasileiras (Brasília, Salvador e Curitiba), para emergir, do primeiro grupo, as representações que guiam seu trabalho e apontam para os integrantes do segundo grupo como suspeitos. Assim, com foco nas ações que compõem a política de combate às drogas, nos debruçaremos em relatos colhidos para entender como, institucionalmente, é reproduzido padrões de preconceito, sobretudo, racial. A compreensão dos depoimentos dos policiais permite captar como preconceitos raciais (em relação aos negros - pretos e pardos) e sociais (relativos à classe) constroem a suspeição reproduzida nas abordagens. Ao mesmo tempo, caminhar pelas narrativas dos jovens negros é descobrir os efeitos de ser essa vida sempre sob suspeita. Ao final, serão feitas considerações, apontando-se para a necessidade de judicialização das práticas policiais, o que permitiria reconhecer, em parte, o status de cidadão a esses jovens e recuperar a legitimidade, senão da policia, ao menos do Poder Judiciário nesse debate.

Palavras-Chave: Suspeito Policial; Juventude Negra; Abordagem; Racismo; Seletividade.

\footnotetext{
1 Professor de Processo Penal e Criminologia da Faculdade de Direito da Universidade de Brasília. E-mail: evandropiza@gmail.com

${ }^{2}$ Doutoranda em Direito na Universidade de Brasília. E-mail: avelar.lais@gmail.com
} 


\section{INTRODUÇÃO}

Cena cotidiana, a abordagem policial expõe seus alvos preferenciais nas ruas dos grandes centros urbanos. Em cidades diferentes - Brasília, Salvador ou Curitiba - a cena parece repetir o refrão que ecoa para dizer que "(...) são quase todos pretos"4. Por sua vez, o crescimento vertiginoso do encarceramento provisório promovido pela Política de Guerra às Drogas e as imagens de degradação da Dignidade Humana de jovens excluídos do mercado formal de trabalho lembra o refrão “(...) a carne mais barata do mercado é a carne negra”. ${ }^{5}$

Nesse cenário, a afirmação de que os sistemas de justiça criminal na América Latina estariam submetidos a uma forma de deslegitimação cotidiana, "pelos próprios fatos" (ZAFFARONI, 1991) soa contraditória. Os efeitos sociais negativos desses sistemas são inúmeros, especialmente porque suas pautas de atuação violam abertamente os Direitos Humanos. Todavia, o silêncio sobre as vítimas desses sistemas é maior. A violência genocida dos sistemas de justiça criminal é acompanhada pelo silêncio público. Qual o papel da percepção do pertencimento racial nesse contexto? Não seria a produção desse silêncio um dos efeitos esperados desse sistema de violência desumanizadora? Como a pesquisa científica poderia colaborar para a compreensão desses problemas?

No contexto do projeto "Quem é o suspeito do tráfico de Drogas" (MJ -SENASP), nos propusemos a investigar a influência de preconceitos raciais e sociais na construção da condição de suspeito presentes na política de prevenção e repressão às drogas. Nossos objetivos específicos eram: a) identificar como a definição racial dada no Inquérito Policial, de branco ou de negro era utilizada na definição da condição de "suspeito", e, a seguir, de usuário ou traficante; b) identificar como se articulava a definição racial com a condição de suspeito ao longo da cadeia de atividades desenvolvidas pela polícia, mesmo antes da formalização do flagrante, nos registros policiais e boletins de ocorrência; c) identificar como a variável racial estava articulada com outras características (ausência de testemunhas além dos policiais que efetuaram o flagrante, prova colhida durante o período noturno, maior ou menor quantidade de droga apreendida, localização geográfica do suspeito - em região com maior ou menor renda -, que veículo automotor o suspeito conduzia e características sociais do local de apreensão). ${ }^{6}$

$\mathrm{Na}$ investigação, além da análise de processos, foram utilizados grupos focais e a aplicação adicional de

\footnotetext{
${ }^{3}$ Doutorando em Direito na Universidade de Brasília. E-mail: rafaeldedeusgarcia@gmail.com

${ }^{4}$ Trecho da música "Haiti" composta por Caetano Veloso.

${ }^{5}$ Trecho da música "A Carne" composta por Seu Jorge, Marcelo Yuca E Wilson Capellette.

${ }^{6} \mathrm{O}$ presente texto foi motivado pelas pesquisas efetuadas em decorrência do Projeto UnB/Direito, "Quem é o Suspeito do Crime de Tráfico de Drogas: A dinâmica e influência dos preconceitos raciais e sociais na identificação e definição das condutas de usuário e traficante de drogas pela polícia" Pesquisa selecionada no âmbito do Edital no 01/2012 do projeto Pensando a Segurança Pública, lançado pela Secretaria Nacional de Segurança Pública do Ministério da Justiça - SENASP e pelo Programa das Nações Unidas para o Desenvolvimento - PNUD.
} 
questionário individual com policiais militares que tivessem atuado na repressão ao tráfico nos últimos cinco anos, e, separadamente, com jovens negros. Intentava-se revelar como padrões de preconceitos raciais e sociais estão presentes na cultura institucional e como esses mesmos padrões são sentidos por aqueles que são suas potenciais vítimas.

As noções de suspeição articulam-se com a seletividade estrutural do sistema penal. No Brasil, alguns estudos trataram da construção dos estereótipos racializados dos suspeitos a partir de uma perspectiva histórica de análise do discurso ou de análise sociológica empírica (DUARTE, 2002, 2014; RAMOS e MUSUMECI, 2005; SILVA, 2009; FLAUSINA, 2008; FORMIGA, 2010) Diante das infinitas possibilidades de criminalização oferecidas pelo mercado de drogas (produção/distribuição/consumo) que gera um número crescente de envolvidos, torna-se ainda mais evidente a noção de que a criminalidade é um processo de atribuição do status de criminoso. Embora faça parte do discurso dominante na esfera pública, a demanda por retirar das ruas as pessoas envolvidas com esse mercado não pôde ser atendida sequer por Estados com muitos recursos públicos. Porém, ela permanece com um apelo simbólico importante numa sociedade cada vez mais excludente.

No caso brasileiro, as análises dos processos de tráfico de drogas demonstram como o poder político dos agentes do sistema de justiça criminal é utilizado para validar processos nos quais a prova é extremamente frágil e insustentável diante de critérios mais precisos de análise. Todavia, tais critérios não são aplicados porque esses agentes, incluindo juízes, estão influenciados por uma cultura jurídica inquisitorial. A vontade de "limpar a sociedade" manifesta-se na microfísica das relações do sistema penal. A aplicação de prisões processuais convertem o processo em pena, na medida em que as condenações muitas vez sequer geram a possibilidade do encarceramento.

O modelo de seletividade do encarceramento resultante surpreende: são processos julgados com debilidade na prova e ausência de critérios matérias de garantia do direito de defesa, nos quais se aplicam prisões processuais que se convertem em penas; prisões fundamentadas de forma ainda mais frágil do que as frágeis sentenças condenatórias. Não bastasse isso, todo o processo estrutura-se na palavra dada pelos agentes policiais. Num contexto em que o controle das práticas policiais é quase nulo, mesmo nos casos mais graves em que ocorrem homicídios, a validação de seus depoimentos abre espaço para a arbitrariedade. A polícia, a qual não se consegue aplicar formas de controle institucional efetivo, torna-se a fiel da balança na determinação da culpabilidade. Enfim, trata-se de um processo estruturado para validar noções de suspeição ao invés de debater publicamente as provas produzidas. O status de criminoso é uma moeda barata que pode ser explorada, inclusive, nas disputas cotidianas. Ao mesmo tempo, o jogo processual sobre as provas desloca-se para argumentos morais sobre o bom e o mal policial, a polícia bem treinada ou mal treinada. Por fim, as críticas ao caráter estrutural desse modelo são rechaçadas a partir dos mesmos critérios que recorrem a imagens da Segurança x Medo, nunca 
submetidos a juízos de validade empírica sobre o controle das taxas de criminalidade.

Malgrado reconheçamos as condições estruturais que possibilitam a seletividade das ações dos policiais, propomos uma análise mais detida dos relatos coletados, pois estamos preocupados em apresentar a gramáticas dos argumentos que permitem a construção de opções de criminalização pelos policiais, e de outra ponta, como a leitura dessa gramática e de suas consequências é reconstruída numa outra gramática que explicita a exclusão sistemática de uma parte da sociedade dos padrões de cidadania. Na análise das informações obtidas nos grupos focais, consideramos que essas narrativas são reveladoras de representações dos interlocutores (PORTO, 2006), assim como de estratégias políticas conscientes de lidar com pesquisadores. Não obstante, o dito e o negado são instrumentos de captação de crenças, valores e preconceitos, capazes de mostrar como é construída a condição de suspeito nas ações preventivas e repressivas da Polícia Militar ao tráfico e uso de drogas ilícitas.

Em síntese, buscamos entender, de um lado, como a imagem do suspeito é construída no discurso policial e, de outro lado, como o estado de suspeito permanente é sentido pelos jovens negros daquelas cidades pesquisadas. ${ }^{7}$

\section{NARRATIVAS DE JOVENS NEGROS E NEGRAS: OS DESABAFOS DE VIVER SOB SUSPEITA E A EXCLUSÃO DA CIDADE}

O critério decisivo para a composição de cada Grupo de Jovens Negros foi ter participado em movimentos negros locais, programas de inclusão para negras/negros ou grupos de discussão sobre relações raciais. Os integrantes são, na sua maioria, do sexo masculino e com idade entre 18 a 30 ano, pois esta faixa etária do sexo masculino têm sido apontada como correspondente ao padrão de seletividade do sistema penal quanto ao quesito raça/cor. ${ }^{8}$ Para formação dos grupos de policiais militares foi estabelecido como critério decisivo a participação em abordagens policiais nos últimos cinco anos, período posterior à lei 11.343/2006, dando-se preferência aos policiais que passaram pela atividade de inteligência de cada PM, pois intentava-se compreender os padrões de investigação, gerenciamento do trabalho e fluxo de informações. A composição dos grupos focais realizados nestas três cidades teve certa variação: em relação à quantidade, à presença do sexo feminino e

\footnotetext{
${ }^{7}$ É importante ressaltar que, em razão da singularidade do tema, foram realizados, em cada cidade pesquisada, dois grupos focais diferentes e de composição exclusiva: um somente com jovens autodeclarados negros (pretos e pardos) e outro composto somente por policiais militares.

${ }^{8}$ Nota-se que RAMOS \& MUSUMECI (2005) afirmam que essa idade máxima seria de 25 anos. Porém, nos grupos focais nos quais encontravam-se indivíduos com até 30 anos, existiram relatos de experiências relacionadas à abordagem policial após a edição da nova Lei de Drogas.
} 
masculino, à escolaridade ${ }^{9}{ }^{10}$, à idade, à cor/raça ${ }^{11} \mathrm{e}$, ainda, no caso dos policiais militares, há uma diversificação no interior dos grupos em relação aos batalhões e patentes ${ }^{12}$

Quanto à metodologia aplicada aos grupos, foram utilizados slides ${ }^{13}$, para guiar atividade, e questionário $^{14}$ temático, para especificar a amostra e coletar informações detalhadas. Os slides permitiram apresentar uma cena de suspeição sem que os pesquisadores tivessem de demonstrar juízos negativos sobre o tema. Por sua vez, os questionários sem identificação, permitiram criar um espaço em que as falas individuais não ficassem submetidas a influência direta do grupo selecionado.

$\mathrm{Na}$ literatura, Gilvan Silva defende que: "A tipologia do indivíduo suspeito descrita pelos policiais militares é constituída por percepções de gênero, étnicas/raciais, geracionais e socioculturais. Descrever a lógica que orienta tal construção necessita de uma reflexão histórica, econômica, política e cultural” (SILVA, 2009, p. 97 98)

A percepção de que a "tipologia" do suspeito é construída em diferentes momentos foi reforçada nos GJNs, porém o pertencimento racial foi destacado. Assim, quando apresentados ao vídeo que trazia uma cena de suspeição, na qual se demonstrava uma reação diferente quando, ao furtar uma bicicleta no parque, o ator era um

\footnotetext{
${ }^{9}$ Em Brasília: Grupo de Policiais Militares (07 - sendo todos do sexo masculino; todos com ensino superior completo, existindo 02 com pós-graduação lato sensu) Grupo de Jovens Negros (08 - sendo 06 do sexo feminino e 02 do sexo masculino; todos estudantes de curso superior); em Curitiba: Grupo de Policiais Militares (15 - sendo 03 do sexo feminino e 12 do sexo masculino; 01 com ensino fundamental completo, 07 com ensino médio completo, 04 com ensino superior incompleto, 02 com ensino superior completo e 01 com pós graduação lato sensu) Jovens Negros (08 - sendo 03 do sexo feminino e 05 do sexo masculino; todos universitários ou graduados) e, em Salvador: Policiais Militares (09 - sendo todos do sexo masculino; 01 com ensino fundamental completo, 01 com ensino médio completo, 03 com ensino superior completo e 01 com pós graduação lato sensu) Jovens Negros (09 - sendo 02 do sexo feminino e 07 do sexo masculino; todos universitários ou graduados).

${ }^{10}$ É importante observar que o número de mulheres no grupo de jovens negras/negros realizado em Brasília foi o mais relevante de todos, seis mulheres dos oito participantes. $\mathrm{O}$ que pode explicar, inclusive, o fato de que houve menos relato de violência quando comparado com os demais grupos.

${ }^{11}$ Sob o ponto de vista da idade e cor, pode-se destacar: em Brasília, todos os jovens declararam-se pretos e todos tinham entre $18 \mathrm{e}$ 24 anos de idade; em Salvador, todos também afirmaram-se pretos e, quatro encontravam-se na faixa etária de 18 a 24 anos, e os demais, na de 25 a 34 anos; já em Curitiba, a maioria autodeclarou-se preto (cinco dos oito jovens) e o restante afirmou-se como pardo e, em relação à idade, apresentou-se o mesmo quadro de Salvador. Nos Grupos de Policiais militares: em Brasília, a maioria declarou-se parda e o restante branco e todos estavam na faixa etária de 25 a 49 anos; em Curitiba, 08 declararam-se brancos, 06 pardos e 01 preto e todos estavam na faixa etária de 18 a 50 anos, por fim, em Salvador: 07 declararam-se pardos, 01 declarou-se branco e 01 declarou-se preto e todos estavam na faixa etária de 25 a 49 anos de idade.

${ }^{12}$ Quanto aos grupos de policiais militares, vale o registro acerca da subrepresentatividade do sexo feminino.

${ }^{13}$ Estas temáticas dispostas nos slides, no caso dos grupos de jovens negros, foram as seguintes: apresentação da pesquisa, percepção sobre o racismo no Brasil, correlação entre negritude e criminalidade para identificação do elemento suspeito, descrição de experiências com a polícia militar e com o serviço de segurança privada e, por fim, as possibilidades e sugestões de melhora nesse âmbito. Para os grupos de policiais militares, os slides traziam as seguintes temáticas: apresentação da pesquisa, descrição das atividades de policiamento, opinião sobre as regras legais de abordagem e sobre a formação, percepção sobre racismo no Brasil, procedimentos de abordagem e, por fim, avaliação sobre a formação.

${ }^{14}$ Os questionários aplicados aos jovens negros, dividiam-se de acordo com os seguintes tópicos: guia de identificação, perguntas gerais sobre atividades de policiamento e vigilância, reflexão sobre o elemento suspeito, sugestões para evitar e diminuir incidentes discriminatórios e, por fim, a opinião acerca do grupo focal. Aqueles aplicados aos policiais militares apresentavam: guia de identificação, perguntas gerais e questões relacionadas à abordagem policial e identificação de suspeitos.
} 
negro abordado sempre como "ladrão" pelos transeuntes - e quando o ator era branco - não questionado -, todos os jovens, dos três grupos (DF, BA e PR), confirmaram que aquela cena poderia se repetir no Brasil. A identificação entre negritude e criminalidade foi apontada como um padrão existente na sociedade:

"A questão que está exposta no vídeo é que os brancos quando são culpados merecem até a dúvida pelo simples fato de serem brancos e os negros não são suspeitos, são culpados. Nós já somos condenados pela cor da pele. Não vai adiantar universidade, carro, dinheiro. Isso está posto. O racismo impede que haja um estado de direito para negros. Não tem saída (...)" (JNBA);

"Se você perguntar a todos no vídeo, ninguém iria dizer que é racista, mas todos se sentiram no direito de questionar o negro. Rola uma intimidação quando vão questionar um branco por estar fazendo a mesma coisa. Quando é um negro, se sentem legitimados a, pelo menos, perguntar alguma coisa. Passa devagar, para, encara, se sente no direito de fazer isso. Quando é branco, as pessoas passam e continuam a vida, não se sentem legitimados a suspeitar. $\mathrm{O}$ suspeito cabe no estereótipo do negro" (JNPR).

Dois depoimentos do GJNDF se destacam, segundo o primeiro: "A cor é prenúncio da culpa." E, para o segundo: o "Negro não pode ser proprietário, porque para ser proprietário precisa ser sujeito de direitos. Ele está na condição de propriedade" (JNDF) ${ }^{15}$.

Entretanto, apesar do intercâmbio existente entre a construção do "suspeito social"16 e o suspeito policial, nota-se que, de acordo com os relatos, os aparatos de segurança (públicos ou privados) reproduzem esta suspeição de forma ainda mais intensa. As percepções dos jovens sobre identificação entre negritude e criminalidade por parte dos órgãos de vigilância e policiamento demonstram como o racismo, presente cotidianamente no cenário social e nos mais diversos níveis de relações, fica ainda mais marcado quando se trata de situações que envolvem relações sociais explicitamente hierarquizadas como no caso do contato com agentes de segurança ou a polícia. Alguns relatos são esclarecedores:

"Lembro de uma situação, eu, universitário, cheio de livros, fui aqui ao Banco XXX, aqui mesmo ao lado, na zona universitária. A gente pensa que tem um tipo de público que atravessa essas ruas. Cheguei na porta da agência, solicitaram que abrisse a bolsa. Eu abri a bolsa- 'não, tira o que tá no fundo'. Esse procedimento sempre tinha comigo algumas vezes, mas nesse dia, extrapolou a coisa. Fui tirando e mostrando que era só livros que tinha, que era só caderno, e continuavam pedindo pra eu tirar. Aí quando estava se formando uma fila de senhoras de classe média alta, a julgar pelo que estavam vestindo, pelo seu sorriso no rosto; tavam começando a se irritar porque a fila estava demorando. Daí a pessoa disse: 'pode guardar tudo e anda logo'. Eu fiquei realmente revoltado, tirei tudo da bolsa, coloquei sistematicamente organizado no chão, virei a bolsa do lado contrário e fiz eles perderem uns

\footnotetext{
${ }^{15}$ Neste momento, é importante sinalizar como, para além da relação feita pela sociedade entre negritude e criminalidade e, como esta suspeição (suspeito social) liga-se à suspeição policial (suspeito policial), emerge nos grupos falas que denunciam a inadequação entre o ser negro e ser proprietário. Esta última fala exposta acima dos Jovens negros em Brasília, pode ser revista no grupo realizado em Salvador. Trazendo novamente o debate sobre negritude e propriedade: "Existe, talvez, a naturalização do patrimônio como o pertencente ao branco. O dono natural, universal."(JNBA). Daí que, diante das argumentações, se ao branco é dado este lugar, ao negro resta a função de usurpador, criminoso, aquele ao qual propriedade surge como ilícito, como inadequação social.

${ }^{16}$ A mídia aparece nos debates com jovens negros como um importante instrumento de reforço e reprodução da cultura racista brasileira: "O negro sempre foi visto como bandido, o que contribui com isso é a cultura midiática." (JNBA)
} 
20 minutos com isso e depois eu fui reclamar com o gerente" (JNPR);

"Tava no carnaval, fiquei no final da Ondina, que é o final do percurso. Fui eu, dois colegas brancos e o tio de um deles. Eu estava de bermuda, camisa, vestimenta típica normal e com o dread que, na minha cabeça, não era pejorativo. Eles [policiais] tavam levando para algum lugar todas as pessoas que estavam sem identidade. $\mathrm{O}$ meu colega tava sem camisa, bermuda, camisa amarrada, e eu estava de camisa. E o cara chegou pra mim me abordando para me levar naquele bolo. Tinha 16 anos. Os demais nem pensar. A abordagem foi em mim" (JNBA);

"Eu estava saindo do parque São Lourenço, estava correndo, sem camiseta, com roupa de correr, com calção de correr, tudo de correr, e dois pesos na mão de $1 \mathrm{~kg}$ e mesmo assim os caras me pararam. Chegaram perguntando pela identidade, mas como eu poderia carregar quando eu tinha ido correr? 'Você está fugindo?'. Falei o nome do policial, olhei pela farda. Não tem nexo, não dá para entender. Ele perguntou 'por que você está correndo?" (JNPR)

Dessa forma, o mesmo padrão seletivo foi relatado nas atividades de policiamento público e da segurança privada. Ambos os serviços atuam com o pressuposto de que negros sempre está realizando (ou na iminência de realizar) uma atividade ilícita ${ }^{17}$.

No GJN realizado em Salvador, destacou-se que a guerra contra as drogas seria uma política direcionada ao genocídio da juventude negra. Ela foi descrita como uma forma de controle populacional. O julgamento social sobre o negro seria determinante de sua morte simbólica ou real:

"Existe uma relação direta entre criminalização das substâncias psicoativas, principalmente da maconha, com a criminalização dos descendentes de africanos.

(...)

É uma estratégia de controle populacional. A maioria da população carcerária feminina é de tráfico de drogas. Articulação bem sofisticada que tem funcionado. Existe sim uma estratégia de luta racial. Há uma inegável luta racial que se completa com a luta de classes com a manutenção do tráfico de drogas pelo Estado" (JNBA);

"Quem é suspeito do crime de tráfico de drogas sempre vai ser a população negra. Quem que aparece sempre como criminoso, como traficante? É a comunidade negra. Infelizmente essa é a realidade" (JNBA);

"Quando o jovem negro usa qualquer tipo de drogas, ele é considerado marginal, ladrão, merece morrer, merece ser punido e a punição vai da humilhação que é morte simbólica na família, na escola, nas encruzilhadas. Antes de chegar a morte física você tem diversos tipos de morte. Pessoas que envelhecem sem esperança, sem saber pra onde ir, o que construir. Isso são formas que você tem de matar, de destruir, de oprimir" (JNBA)

A leitura dos questionários e depoimentos mostram três pontos centrais: a) seletividade na abordagem (negros como alvos dessa atividade policial) e diferença na forma da abordagem feita com o negro em relação àquela feita com o branco; b) recorrência à ideia de estereótipo e c) uso da abordagem sem uma justificativa prévia e utilização do argumento do "procedimento padrão".

\footnotetext{
${ }^{17}$ A máxima diferença entre esses serviços, como posto pelo grupo de Curitiba, está no poder que os policiais detêm em relação ao segurança privado: "(...) Eles [segurança privado] têm a possibilidade de exercer a violência sobre a pessoa, mas não têm o poder."(JNPR). E continua: "(...)A diferença entre um [segurança] e outro [policial] é que o policial pode colocar um flagrante na tua calça e tem um termo lá que legitima a descrição dele." (JNPR). Todavia, apontada a diferença, registra-se como, mesmo no campo privado, a violência frente ao povo negro ultrapassa os campos simbólicos: "(...) O segurança não tem essa possibilidade, o máximo que pode fazer é te levar pra salinha, te dar umas bicudas e te mandar embora, ou te entregar para a polícia e se tornar a extensão da polícia." (JNPR)
} 
Neste contexto, e em relação ao primeiro destaque, tanto em Salvador como em Curitiba, as afirmações dos jovens apontaram para a existência de um filtramento racial (racial profiling) que seleciona como alvos preferenciais os negros (pretos e pardos). Este filtramento "descreve o uso pela polícia de meios racialmente tendenciosos para identificar suspeitos e/ou buscar e capturar cidadãos."18 (AMAR, 2005, p. 231) orientando, assim, condutas e práticas policiais, sobretudo a abordagem. Eis alguns exemplos:

“(...) o racismo institucionalizado na corporação em que direciona a relação entre polícia e população negra onde a segunda tem o estereótipo de criminosa. Outro fator é a caracterização do suspeito padrão em que são encaixados os negros" (Q7/BA);

"O racismo institucional está incorporado às práticas policiais." (Q4/PR);

"Essa distinção na abordagem policial é em decorrência de fatores históricos atribuídos à sociedade negra em um passado distante. Desde a época da escravidão os negros já sofrem por este tipo de perseguição.(...)." (JNDF)

"Sendo o país historicamente racista, a polícia, uma instituição, essencialmente, preconceituosa e sem qualquer tipo de diálogo para os temas relacionados a cor da pele e [sendo] Salvador uma cidade eminentemente, negra, é mais que decisivo a cor da pele influenciar na abordagem e na identificação do 'suspeito.'. (Q8/BA)

Cabelos blacks, uso de dreads, roupas que se relacionam à cultura rap (blusas ou bermudas mais largas,

boné...) ou, simplesmente, o fato de ser um negro com o tom da pele mais escura, produzem o "efeito estereótipo"19 e a suspeição torna-se ainda mais "automática"20 . Senão, vejamos:

"São reforçados vários estereótipos em relação ao negro, por isso a forma de se vestir, de andar, de falar são uns dos muitos outros fatores usados pela polícia para abordar mais negros do que brancos" (Q6/BA);

"Possuir traços fenotípicos negros é um fator determinante para a 'parada policial', e quanto mais melanina, pior" (Q5/PR);

"Uma vez eu tava na escola, com blusa de rap, boina de rap, correto na escrita 'preto do gueto'. Foram fazer revista na sala a pedido da professora, porque fizeram uma denúncia lá. Meu irmão, da minha cor, estava de camisa e calça jeans. Na sala, revistaram todo mundo: mulher, tinha de abrir a bolsa; rapaz, mostrar tudo o que tem. Isso dentro da sala de aula no ensino médio. Chegaram em mim, revista de 15 minutos; no meu irmão, 5 minutos" (JNPR);

\footnotetext{
${ }^{18}$ O diálogo de AMAR (2005) com Steve Martinot revela como o filtramento racial produz uma estrutrura de racialização. Assim, para além da criminalização da raça, passa-se a racialização do crime: o comportamento negro, ilegal ou não, passa a ser sinônimo de delito. Chamamos atenção para como essa inversão (criminalização da raça para racialização do crime) não pode ser encarada como mero requinte teórico: há um substancial impacto no plano concreto. Neste sentido, o que há, agora, não é mais só a criminalização de certos indivíduos mas, acima de tudo, a identificação do comportamento/traços socioculturais destes certos indivíduos como criminoso - subsunção do ser negro em ser criminoso.

19 É interessante a observação feita por BROOKSHAW (1983) na qual explica "(...)que os estereótipos estão mais enraizados no preconceito do que no fato, eles são tão flexíveis na prática quanto inflexíveis na teoria." (BROOKSHAW, 1983, p.11) para pensarmos como os estereótipos não são incompatíveis, pela sua flexibilidade prática e inflexibilidade teórica, aos conhecimentos dinâmicos e práticos. Ao contrário, podemos até mesmo dizer que os estereótipos, numa cultura autoritária, podem ser o cerne de saberes práticos, situacionais e dinâmicos.

${ }^{20}$ Os relatos também fizeram referência ao local como fator determinante para abordagem. Aqui nota-se que, tanto o local periférico, marginalizado, como o local situado em áreas nobres da cidade operam como elemento influente. O primeiro, local socialmente e racialmente segregado, pelo fato de serem zonas onde a abordagem policial ocorre intensamente e, o segundo, regiões que concentram população predominantemente branca de médio ou alto poder aquisitivo, em razão da presença do negro ali ser automaticamente entendida como inadequada, causar "estranhamento".
} 
"Cabelo crespo; nariz largo; lábios grossos; maior concentração de melanina" (Q3/PR);

"A época que eu tinha dread foi muito maior, nem se compara [referindo-se à quantidade de abordagens]" (JNPR);

"Quanto mais claro você é, mais fáceis são as rotas de escape, as válvulas de escape que você tem na sociedade para ter uma vida melhor, mas mesmo assim tem a questão da vestimenta: boné na cabeça, roupa mais largada. A polícia sabe identificar quem é negro, quem é branco" (JNBA);

"Cabelo; roupa; andar; música; religião" (Q1/BA)

Os GJN, sobretudo os de Brasília, revelaram a questão da arbitrariedade das abordagens, denunciando a ausência de alguma justificativa aparente ou alegada. "Isso é muito importante. Imagine você ser abordado e não saber o porquê. Eu tô na rua, 8h da noite, por exemplo, e fui abordado.(...)" (JNDF). A abordagem feita sem justificativa representaria a arbitrariedade policial e o abuso do poder discricionário que lhes é conferido.

Os GJN identificaram como mera estratégia argumentativa - apenas quando não se encontra nenhum ilícito na abordagem, e apenas após sua ocorrência - a alegação do "procedimento padrão". É o que infere da fala: "(...) depois ele explica que foi simplesmente um procedimento padrão, isso não pode acontecer, porque um procedimento padrão é uma desculpa muito genérica.(...)" (JNDF). Mesmo assim, nem sempre a alegação do "procedimento padrão" está presente, sendo mais frequente, como se observou, quando os policiais envolvidos percebem que o indivíduo negro abordado tem um status social diferente (em referência a fatores como escolaridade, localidade de residência ou poder aquisitivo):

"Todo mundo aqui tá chamando a atenção de quando 'ah, porque meu amigo ou eu no caso foi abordado' e sempre o policial fala 'não, mas isso é procedimento padrão'. Mas ele toma essa atitude de certo polimento sempre depois que descobre que o jovem que ele abordou é um jovem com algum grau de escolaridade ou mora de num lugar ou tem um poder aquisitivo. Ou seja, se fosse um jovem de alta vulnerabilidade social, ele não corrigiria a atitude dele. Ele não voltaria atrás e diria que é um procedimento padrão. Ele iria colocar o jovem num camburão e iria levar pra delegacia (...). Alguns negros podem ser levados no camburão, outros 'eita, não, peraí, esse aqui faz UnB'. Esse aqui é procedimento padrão, mas só é procedimento padrão porque você é estudante, é universitário, porque você é um dos poucos negros de classe média, se não, não era procedimento padrão. Deve [deveria] ter um procedimento único para todas as pessoas independentemente de sua tipologia ou origem.(...)" (JNDF);

"Não se desculparam nem nada, nem disseram que era procedimento padrão, apenas entraram no veículo e foram embora" (JNPR).

$\mathrm{Na}$ descrição das abordagens policiais, depoimentos sobre agressões verbais e/ou físicas se repetiram ${ }^{21}$.

Ordens claramente humilhantes, ameaças, violência física, produção de provas de forma ilícita aparecem nas narrativas dos jovens negros que apontam os policiais militares como promotores de violência reproduzida nas suas ações:

\footnotetext{
${ }^{21}$ É preciso lembrar que o grupo de Brasília foi composto por uma maioria significativa de jovens do sexo feminino (dos oito presentes, seis eram do sexo feminino) e o que pode explicar, em parte, que, diferente de Salvador e Curitiba, o fato de não ter sido destacado confrontos pessoais diretos com os policiais. Entretanto, devemos frisar que a visão desses jovens sobre a polícia era
} 
“A abordagem básica ocorre assim: 'mão na parede'; se não tiver parede, 'mão na cabeça'; 'vira lá. O cara chega por trás, se você está com a perna fechada, ele chuta pra abrir; se está aberta, chuta pra fechar. Começa por baixo, quando chega no saco, ele dá um tapa com força. Os excessos vêm da gracinha, um tenta fazer graça pro outro contigo, é assim que começa (...)

Às vezes dizem 'isso é procedimento padrão', 'você teve sorte', qualquer graça, não tem regra. Mas sempre tem alguma gracinha, alguma 'ah, dessa vez, você teve sorte, escondeu bem', 'eu te conheço', 'vamos passar aqui de novo, vamos te pegar daqui a 5 minutos'” (JNPR);

"Já fui abordado pela Caatinga, que eu não sei se ainda tem, mas tinha na roupa 'pai faz, mãe cria, caatinga mata' e ele falou que se me pegasse novamente eu não ia só ler aquilo. Eu tinha 14 anos" (JNBA);

"A Choque, como ela faz a abordagem, é uma polícia bem violenta. E quando eles não levam o sujeito preso, mandam o sujeito sair correndo e gritando 'choque é barril', exaltando essa questão da violência que há na corporação" (JNBA);

"Tive minha casa invadida umas duas vezes. A base de truculência, violência. Tava eu, um amigo, minha filha, meu cunhado. Roubaram uma moto na comunidade. A polícia chegou, tentei dialogar, mas não consegui. Eu não sabia de nada. Foi durante o dia, 13h. Foi uma situação muito desagradável, de impotência. O acesso ao ensino formal te dá empoderamento, mas naquele momento não tive poder. Essa foi uma das situações. Em outro momento meus pais tiveram a casa invadida. Havia denúncia de traficante na área. A polícia invadiu umas 05 casas. Não teve um pedido de desculpas, não teve mandado legal para agir dessa forma" (JNBA)

Alguns relatos são ainda mais precisos quanto à letalidade e ao genocídio promovido ${ }^{22}$ :

"Meu irmão foi morto pela polícia sem motivo algum. Saiu na mídia, no jornal: um homem branco de 25 anos e um homem negro de 33, com 'aparência perigosa'. Nunca teve prova, foi tudo arquivado" (JNPR);

Por fim, é interessante notar as respostas nos diferentes grupos de jovens quando perguntados sobre estratégias e possibilidades para melhoria dos procedimentos de abordagens. Em Brasília, as várias sugestões podem ser aglutinadas em dois grupos mais amplos: a necessidade de um verdadeiro procedimento padrão (não aquele que é dado apenas como desculpa genérica de forma a esconder arbitrariedades, incluindo a necessidade de identificação prévia do policial) e a necessidade da informação (informar o motivo da abordagem e a defesa de um diálogo para maior aproximação com uma polícia que respeite os direitos dos cidadãos). Para exemplificar:

"Primeiro de tudo acho o policial esteja identificado. Acontece muito de policial não estar identificado, só estar fardado e te abordar.(...)" (JNDF);

"Eu acho que também é a questão da informação. A polícia chega e não fala nada. É só vou te abordar e te dar uma justificativa muito genérica. Então uma informação mais específica, explicando por que ela está te abordando, o que ela vai fazer com você. Diálogo, sabe?" (JNDF).

A respeito de sugestões, possibilidades ou expectativas de melhorias na relação com a polícia, os jovens negros, principalmente em Salvador, demonstraram alta desconfiança em relação à instituição. "[A polícia] Faz papel colonial. Não existe diálogo com o senhor. Ela cumpre esse papel” (JNBA). Foi bastante comum a

extremamente negativa. Traduzida por significantes como "despreparada", "desinformada" e "que reproduz estereótipos", os quais surgiam nas falas a todo tempo.

22 Apesar dos vários relatos de agressões verbais e físicas sofridas durante abordagens policiais por parte dos jovens negros em Salvador e Curitiba, a grande maioria não realizou qualquer denúncia às autoridades por medo de repressão. 
referência à questão da desmilitarização como forma de reduzir a violência policial e como meio para melhoria do diálogo.

\begin{abstract}
"Acredito que nenhuma atitude paliativa teria um resultado eficiente. A instituição policial precisa passar por uma reestruturação que inclui a desmilitarização da polícia militar. A melhor formação dos profissionais e o reconhecimento do policial como protetor da sociedade, e não um assegurador da 'ordem"' (Q2/BA);

"Em primeiro momento, a conscientização dos policiais acerca da institucionalização do racismo teria grande impacto. Dessa forma, o policial perceberá que este é um problema também do aparato policial e não externo a ele. Em segundo momento, fica claro que a desmilitarização seria um redutor da violência, porque permitirá uma relação horizontal com uma maior interação entre as partes, fazendo com que a população discriminada se sinta aceita ou melhor vista perante o Estado" (Q1/BA);

"Uma reestruturação na formação da polícia, a desmilitarização da mesma, uma formação focada na raça e no gênero" (Q6/BA)

"Espero que a polícia acabe, que haja uma desmilitarização, que a PM deixe de existir. Nem sei se incorporando a PM com a PC diminuiria a violência. Parece que isso é mais fruto de um procedimento de formação, o curso da polícia do que do exercício do dever policial. Sei lá, uma revisão desse curso de formação da polícia seria de grande ajuda.(...)Mais concreto, eu queria que não me batessem, não precisa nem chamar de senhor, de cidadão" (JNPR);

"Um programa de reciclagem na polícia, que tenha como foco as mudanças no racismo" (Q4/PR);

"No treinamento da polícia deveria ter um modo de abordagem mais definido (um modo padrão), de modo a respeitar os cidadãos com igualdade" (Q7/PR).
\end{abstract}

\title{
AS NARRATIVAS DE POLICIAIS MILITARES: DEMOCRACIA RACIAL E NEGAÇÃO DO RACISMO INSTITUCIONAL
}

O objetivo da realização de grupos focais e aplicação de questionário com policiais militares foi o de captar - a partir das descrições sobre as suas atividades de policiamento e de abordagem na repressão ao uso e ao tráfico de drogas ilícitas - as percepções quanto à reprodução de padrões racistas nas práticas de abordagem. Para tanto, era evidente a necessidade de compreender o funcionamento do conjunto das atividades relacionadas à repressão e prevenção do tráfico de drogas. A complexidade dessa rede de decisões fica evidenciada num dos depoimentos:

"A identificação pode ser feita por meio de denúncia anônima, onde são passadas as características do elemento suspeito, como a roupa que está vestindo, boné que está usando, tatuagem, ou através de investigação ou até mesmo reconhecimento pelos policiais, por se tratar de um elemento conhecido pela polícia pela prática de tráfico de drogas" (Q1/BA).

Apesar dessa complexidade (atuação a partir de denúncia anônima, denúncia da comunidade, aquela baseada numa investigação prévia ou, ainda, por iniciativa do policial), é relevante registrar como, nos três grupos, a iniciativa do próprio policial foi destacada como determinante para as abordagens nas ruas. Um dos integrantes do GTOp, Distrito Federal, afirmou que 70\% a 80\% das abordagens partem da iniciativa do policial. Os três 
grupos exaltaram o "tirocínio policial" como fator fundamental para uma abordagem bem-sucedida. O tirocínio se refere ao "faro", ao elemento subjetivo que o policial desenvolve em saber, por instinto ou sensibilidade, quais são as condutas e elementos que são de fato suspeitos. Revelaram, desta forma, a subjetividade que pode permear a suspeição:

"Hoje, 100\% das abordagens não são repassadas por uma central. É do instinto policial mesmo. Local de risco, local de constante consumo de drogas. O policial naquela região já está mais ligado" (PMPR);

"As apreensões acontecem muito mais por uma abordagem bem sucedida dos policiais do que por ordem de serviço. Por tino policial" (PMPR);

"Na carreira usamos as três identificações, tanto por parte tomada pelo agente, por informações dada na central, e por investigações. Porém o de maior ocorrência é o "faro" policial" (Q4/BA);

"Já conseguimos 03 metralhadoras por causa de 01 usuariozinho. Se a gente trabalha o dia a dia e não prende ninguém, a gente fica triste. Agora a gente sabe a diferença entre quem tem que apertar ou não. Não é qualquer um não" (PMBA).

Em seguida, intentou-se compreender o impacto das demandas sociais no policiamento. Os relatos indicam que o policiamento também é realizado para atender aos "anseios da comunidade", ou seja, parte do policiamento é lastreado por informações oriundas de atores sociais, como pessoas do ambiente escolar e comerciantes locais ${ }^{23}$ :

"Recebemos muitas informações da escola, dos pais, dos professores. As maiores informações que chegam para nós é de dentro da escola" (PMPR);

"Tem vários comerciantes, a população também, então sempre tem algum tipo de contato. Vai passando algum tipo de informação para a gente. Contato é fundamental. 190 ajuda bastante no levantamento. Só que a comunidade não é toda ela que vai ligar"(PMDF).

Em relação à identificação de suspeitos nas ações de combate ao uso e tráfico de drogas ilícitas, assumese a utilização de elementos como local, vestimentas, linguagem e, principalmente, a atitude do indivíduo ao avistar a polícia ${ }^{24}$. Somado ao discurso do tirocínio policial, com valorização do policial "mais velho", "experiente", tem-se $o$ discurso da atitude suspeita. Foi comum, nos três grupos, a negação de que a suspeição se deve a características físicas do acusado. Foi padrão a afirmativa de que se utilizam apenas elementos como local,

\footnotetext{
${ }^{23}$ As duas citações postas acima simbolizam duas demandas que, especialmente, em Brasilia e em Curitiba, apareceram com frequência - originada de atores da escola e comerciantes. Além da clara função de valorização do trabalho policial, a referência às redes de informaçôes estabelecidas a partir da comunidade, revela um contato forte com os comerciantes e a polícia. Este intenso fluxo de informações (comerciantes locais e polícia) sinaliza uma naturalização do uso do aparato policial para a proteção de determinados bens privados.

${ }^{24}$ Acerca do critério para abordagem baseada na atitude do cidadão ao avistar a polícia, valem duas considerações. A primeira é que ao atentarmo-nos nas falas perceberemos que a descrição da reação suspeita abarca uma gama enorme de comportamentos (correr, "qualquer alteração mínima", olhar para o lado, voltar para casa, entrar num estabelecimento,...) o que deixa a impressão de que o suspeito já está feito independente de seu comportamento que servirá como mera justificativa para afugentar questionamentos. A segunda consideração diz respeito ao perigo da determinação de abordagem com base nesta leitura vaga de reação do indivíduo diante da presença policial. Isto porque por serem vistos como criminosos, por estarem sempre sob suspeita, é razoável pensar que integrantes de grupos vulneráveis demonstrem maior nervosismo, insegurança ao avistarem uma viatura ou um grupo de policiais. Traduzindo: a consciência que a sua negritude já vincula-o à criminalidade, produz exatamente o efeito esperado e "justificador" para ação policial, gerando um ciclo vicioso de abordagens e incriminações.
} 
vestimentas e atitudes do cidadão, o que contraria frontalmente o alegado pelos jovens negros.

"Pra a gente, fundada suspeita é a atitude. Atitude do elemento. O policial que trabalha numa área ele conhece, ele sabe onde as pessoas que geralmente cometem esses delitos andam. A gente tem as características dessas pessoas. Geralmente as vestes, o que elas estão usando" (PMDF);

"E através da experiência, tempo de serviço, estudos, o policial passa a identificar os elementos com mais facilidade, inclusive conhecendo muitos" (Q6/DF);

"A gente se baseia muito na localidade, na forma de se vestir, na linguagem da pessoa. Linguagem de marginal era busca pessoal na certa" (PMBA);

"Qualquer alteração mínima de qualquer pessoa quando a gente está chegando já é considerado motivo de abordagem. Se ela se assustar, olhar pra um lado, olhar pro outro, correr, andar mais rápido, te dar as costas" (PMBA);

"Todo mundo observa a viatura. $\mathrm{O}$ indivíduo suspeito às vezes é o cara que não olha; tem uma atitude diferente; dobra a primeira esquina; entra no primeiro estabelecimento que vê, nem que seja uma loja de lingerie, só para disfarçar; acabou de sair de casa, pega e volta" (PMPR);

"No curso de formação de soldado, eles tentam traçar um perfil e pelo o que eles falam quem traçou um perfil foi justamente Lombroso. E não tem perfil. Tanto é que não é o elemento suspeito, é a atitude suspeita" (PMDF);

"Fundada suspeita na academia são aquelas situações. Não é como Lombroso falava. Dependendo do clima, a roupa que a pessoa está vestindo; volume na área da cintura. Não se dá por biótipo, características físicas e sim por situações adversas da pessoa." (PMPR).

Contudo, a contradição é percebida quando são dados exemplos de suspeições. Nesse momento, algumas falas são explícitas e outras, ainda que mais sutis, revelam a identificação de suspeitos baseada em percepções de características ligadas à raça e à classe social. Assim nega-se, inclusive, o caráter "vazio" e "intuitivo" do tirocínio policial, o qual escamoteia um acúmulo de preconceitos:

"Não vou negar que não há um certo determinismo pelo policial. Aquele carro ali tem determinadas características, aquele cidadão tem determinado perfil" (PMDF);

"A gente sabe o que está fazendo em função de o serviço ser rotineiro. Algumas situações nos passam despercebidas porque a pessoa não tem essas características que a gente espera que ela tenha" (PMDF);

"Acho que foi domingo mesmo fizemos uma abordagem na Ceilândia. Abordamos um cidadão que estava com um bermudão com o estilo mais largado, camisa mais aberta, boné, negro. Desceu do carro dele. Fizemos a abordagem normal. Promotor de Justiça. É muito relativo" (PMDF);

"(...)a gente sabe a diferença entre quem tem que apertar ou não. Não é qualquer um não" (PMBA);

"Na maioria das vezes pelas características físicas e psíquicas, locais, onde andam ou estão, frequentam. Pelas demais pessoas demais pessoas que convivem. Pelos horários e locais que frequentam" (Q14/PR).

Para captar as percepções dos militares sobre o preconceito racial na sociedade brasileira, a mesma cena

do documentário passado nos grupos de jovens negros foi exibida nos grupos focais. Entretanto, ao contrário do que o ocorreu nos grupos focais com jovens negros, predominou o entendimento de que a cena do vídeo (que ocorreu nos EUA) não faria sentido no Brasil, afirmando-se:

"A parte do negro e do branco não faz muito sentido. A gente não pode considerar porque aqui no Brasil, comparado com um filme estrangeiro... Lá o preconceito é muito grande. Eles 
vêm de uma cultura diferenciada. Aqui eu não concordo muito com isso. Acho que no Brasil não tem muito disso" (PMPR).

Em Brasília, 04 dos 07 policiais integrantes declararam, nos questionários aplicados, não haver racismo contra negros no Brasil. Em Curitiba, 07 dos 15 responderam da mesma forma e, entre estes, um comentário chama atenção pela tentativa de deslocamento de culpa:

"Creio que os próprios negros são mais racistas que outras raças. Separam-se em grupos e sempre usam o mesmo termo quando não conseguem o que querem: 'só porque eu sou negro"” (Q11/PR).

Já em Salvador, apenas 01, dos 08 que responderam ao questionário, declarou não haver racismo no Brasil. Todavia, apesar da diferença em relação às respostas das outras cidades, os militares baianos, assim como os demais, reforçaram que a suspeição no Brasil estaria mais fundada na questão sócio-econômica. Todavia, observase nas respostas que não houve dificuldade em assumir outros preconceitos:

"Às vezes não é pela cor. Ele pode estar de pés descalços, de roupa suja, mexendo numa bicicleta que nem aquela. O padrão de vestimenta acho que interfere demais" (PMPR)

Ao serem indagados com a pergunta "Considera que negros e brancos são abordados da mesma forma pela polícia e com a mesma frequência na região que atua?" tanto nos questionários como nas conversas, a maioria respondeu não existir distinção, negando a presença do racismo na atividade policial. Podem ser observados diversos argumentos para essa negação, inclusive a transposição da ausência de preconceito na sociedade brasileira para negação deste na prática policial, como podemos notar:

"Tem muita gente que ainda insiste em vincular. Isso se vê mais nas reportagens dos EUA em que o policial sempre tem raiva da pessoa de cor negra. No meu caso as pessoas que trabalham comigo, nunca vi por parte de nenhum deles esse tipo de discriminação. Normalmente, a gente faz em função da vestimenta e do local. Aí não é discriminação não" (PMBA);

"As pessoas são abordadas por fundadas suspeitas e não baseada em questões raciais" (PMPR);

"Pelo fato da Bahia ter uma população mais negra, o tratamento pela etnia é igual" (Q5/BA).

Entretanto, no desenrolar da entrevista começam a surgir relatos que, em alguma medida, deixam transparecer o preconceito racial inicialmente rechaçado:

"Se estiver na Ceilândia, num lugar muito sinistro, não vai dar uma frase de boas vindas. Você vai mostrar energia na sua ação. Se você está aqui no Plano Piloto, numa situação mais confortável, vai chegar num bar de forma diferente, pelo menos na verbalização, do que na Ceilândia" (PMDF);

"Bahia é uma mistura danada. Acho que não tem muito isso não. Bairros classe A pode existir um pouco. Por parte da PM, aborda todo mundo. Acho que, se tiver 2 negros de um lado e 2 brancos do outro, o policial vai abordar primeiro os negros. Isso é uma tendência já. Pode ser até uma discriminação, mas interiorizada. Para ele não é uma discriminação. É uma coisa enraizada nas nossas mentes" (PMBA);

"A preferência por abordar o negro é um ponto não da PM, mas da sociedade, cultural" (PMBA).

Não obstante, ao serem confrontados com as assertivas dos jovens negros no sentido de serem alvos preferenciais das práticas policiais, sobretudo das abordagens, os militares saem em defesa própria. Alegam uma 
"síndrome de vitimização" do próprio negro - afirmando, inclusive, que as argumentações dos jovens não seriam verdadeiras. Porém, relatam uma estratégia utilizada no cotidiano para se "isentar" de uma eventual acusação de preconceito racial, consistente em solicitar a outro policial também negro a realização da abordagem. Trata-se de verdadeiro gerenciamento das relações raciais como forma de deslegitimar uma alegação ou denúncia de atitude racista $^{25}$ :

"Eu particularmente vejo dessa forma. Muitas vezes a gente está abordando uma pessoa e ela pensa: está me abordando porque eu sou negra. Mas a minha atividade é essa. Eu tenho que abordar. Existe uma cultura ainda aqui que negro é perseguido. Mas a culpa não é da polícia. Somos ferramenta do Estado" (PMDF);

"O preconceito vem da própria pessoa, por ela ser negra ou pobre ela já fala que está sendo abordada por isso" (PMPR);

"Uma vez estávamos no posto de gasolina, chegou um carro. Visualizamos a atitude suspeita e fizemos a abordagem. Eu particularmente fui o primeiro a chegar e fazer a revista no cidadão. O cidadão e falou: 'o senhor só está fazendo isso em mim porque eu sou negro'. Eu fiquei com raiva dele ali naquele momento. Peguei nele com certa energia, virei ele pra trás e mostrei meu companheiro de quase 2 metros de altura, negão. Aí eu mostrei pra ele e falei: 'aqui, ó, o camarada está falando que eu só estou abordando ele porque ele é negro, então você faça a abordagem’. Aí o negão fez a abordagem. Ele preferia que tivesse sido comigo" (PMDF);

"Geralmente eu tenho sorte nisso, porque o sargento com que eu trabalho é negro. Passa para ele para o cidadão ver como funciona, para ele ver que não é por conta disso. Só que infelizmente isso é cultural. A gente vivencia num país que tem essa cultura" (PMDF).

Quando perguntados sobre sugestões para evitar os incidentes em que os indivíduos abordados sentem-

se discriminados por sua cor ou raça, a atitude mais comum foi a de negar a existência de preconceito racial.

Houve, entretanto, uma forte defesa da estratégia de aplicação do princípio da igualdade à abordagem que, no fundo, traduz-se na defesa de generalização desta, ou seja, submissão de todos sem contestação à ação policial:

"É uma pergunta que não posso responder pelos outros, mas da minha parte e da parte dos policiais que trabalham comigo, não acontecem incidentes em relação à discriminação" (PMDF);

"Abordagem tem que ser feita a todos que estão num ambiente ou ônibus" (PMBA).

Nos grupos dos policiais militares o debate sobre a "Guerra contras as drogas" foi importante para captar também as percepções destes sobre a eficácia do seu trabalho. Falas como: "O meu contato era mais com o usuário e com os pequenos traficantes, que a gente chama de avião. Nunca peguei peixe grande" (PMBA) ou "Você não vê traficante caindo na abordagem. Você vê peixe pequeno. Traficante é um patrão, tem dinheiro, tem poder" (PMPR) se revezavam. Ficando evidente que o policiamento comum tem contato muito maior com o usuário e que, diante disso, o policiamento ostensivo seria pouco eficiente.

Contudo, essa constatação gera, ao mesmo tempo, duas estratégias, que em comum tentam legitimar a

\footnotetext{
${ }^{25}$ Este procedimento legitimador articula-se à defesa da síndrome de vitimização. $\mathrm{O}$ negro, que segundo o policial enxerga-se imotivadamente como "perseguido", ao reclamar que está sendo abordado em razão de sua cor/raça, deve ser passado para um policial negro para ver como pode ser punido mais severamente por um de seus "iguais". Um claro processo de dupla punição: por ser negro e por ter reclamado.
} 
ação da policia militar mesmo diante da ineficiência, em parte, reconhecida: adoção de discursos que valorizam moralmente a função da Polícia Militar numa luta do bem contra o mal nas ruas e, como segunda estratégia, a defesa de que a não repressão de pequenos delitos conduziria à pratica de delitos mais graves - uma apropriação "popular" da teoria das "janelas quebradas". Como veremos, tais argumentações parecem se confundir nas falas e produzem, em sua conclusão, uma indistinção entre o usuário e o traficante:

"Se for comparar a polícia a traficante, a drogas é comparar o bem contra o mal. Vai ser a vida inteira assim. O que a gente faz, a gente sabe que muitas vezes não é situação que vai mudar o panorama daquela situação. Mas se a gente desanimar disso e não levar aquele cara que tá um cigarro de maconha, aquele cara que tá com duas pedrinhas de crack, enquanto a lei disser que é portador de substância entorpecente, se todos nós começarmos a achar que nosso dia a dia não tá evoluindo a nada, a tendência é sempre piorar. E daí muitas vezes a gente diz assim 'ah, eu tô com meu filho lá em casa, a minha preocupação é meu filho, quero mais que se ferre, eu não abordo, não vou atrás de informação'. Só que ele pode ser vítima amanhã ou depois da droga que chegar lá na casa dele pro filho dele.(...)." (PMPR);

"O usuário eu também levava, porque no mínimo ele ia ficar sujo lá, com uma entrada. E a probabilidade dele virar um traficante, um avião é muito grande" (PMBA);

"Eu levo mesmo, porque eu sei pode até não ficar, mas tem o registro. Quando ele comete um delito aí a mãe diz: 'meu filho não tem uma entrada'. Porque futuramente ele vai dar trabalho pra gente. Ele tá cometendo um ilícito. Se tivesse trabalhando eu não levava ele preso. Futuramente a gente vai ser vítima, os filhos do senhor, os filhos do capitão.(...)Eu acho que se tivesse uma punição maior tinha que ser pra quem compra. Ou então a justiça obrigar a ele ir para um centro de recuperação. Eu li uma matéria que nos Estados Unidos ou ia pro centro ou ia preso" (PMBA);

Ao fim do debate, os policiais eram questionados quanto à formação recebida nas academias e a atividade desenvolvida nas ruas. As falas mostraram insatisfação com o ensino teórico da Academia, apontando como o procedimento padrão, supostamente objetivo e impessoal, apreendido na formação, é insuficiente para compensar algumas "regras de experiência" do "código das ruas", os quais, com vistos, explicitam padrões preconceituosos de abordagem. A fala feita por um policial baiano resume bem:

"Teoria e prática são duas coisas totalmente diferentes. Na rua a gente aprende alguns vícios, como dizem. Alguns modos de chegar. Não vou dizer que o curso foi péssimo nem vou dizer que foi bom. É do interesse da pessoa também. Antes de botar na rua tinha que ter uma orientação, colocar com que já tem muito tempo. Botar o problema na sala de aula" (PMBA).

Por fim, segundo os policiais entrevistados, o tema do preconceito racial, especialmente, enquanto possibilidade de ser reproduzido nas ações policiais (como as abordagens), não é trabalhado diretamente na Academia de Polícia.

\section{CONSIDERAÇÕES FINAIS}

A análise das narrativas presentes nos grupos focais com jovens negros pode ser sintetizada nos seguintes elementos: a) negritude e criminalidade estão imbricadas na sociedade, de modo que a cor é "prenúncio da culpa" 
e de que há uma distância do negro da condição de proprietário; b) negros são muito mais submetidos à condição de suspeito e a abordagens; c) prevalência do jovem negro como alvo da política de repressão às drogas; d) apesar de a cor da pele ser elemento de suspeição principal, as características culturais da negritude também são alvo da suspeição policial; e) intensa arbitrariedade nas abordagens policiais, sempre com falta de diálogo e, por vezes, quando há, a presença do subterfúgio argumentativo do "procedimento padrão"; f) abordagens e revistas pessoais com violência física e ameaças, inclusive de morte; g) desconfiança com a possibilidade de mudança da cultura institucional da PM, mas com sugestões de desmilitarização e abertura para o diálogo.

Em razão da impossibilidade de nos alongarmos mais, preferimos usar este espaço final para sugerir algo que entendemos como urgente.

Por sua vez, a análise das narrativas presentes nos grupos focais com policiais militares pode ser sintetizada nos seguintes elementos: a) o tirocínio policial é o principal elemento na definição de suspeitos, com reconhecimento de critérios meramente subjetivos; b) todavia, o tirocínio, muito embora signifique seletividade (por raça, classe e região) não significa, como pretendem alguns policiais, uma habilidade refinada de encontrar potenciais criminosos, mas a habilidade apreendida de exercer violências contra grupos determinados: c) a importância da participação da sociedade na definição dos suspeitos, principalmente de agentes vinculados a comércios locais e instituições escolares, muito embora a segunda seleção executada pelos policiais, responsável por validar as percepções da comunidade, seja decisiva na ação efetiva de abordagem; d) a presença do discurso da atitude suspeita, com negação de critérios discriminatórios na definição de suspeitos, é um discurso difundido, mas incapaz de encobrir totalmente padrões discriminatórios de suspeição; d) negação, ainda que parcial, da existência de racismo na sociedade brasileira; e) alegações de que a população negra sofre da síndrome de vitimização, invertendo a lógica de quem seria o agente racista; f) presença de um gerenciamento das relações raciais no interior da corporação, na medida em que se coloca, propositalmente, o policial negro para abordar um negro justamente para fugir da alegação de racismo; g) desejo de que se aumente os poderes policiais quanto às possibilidades de abordagem e de revistas pessoais; $h$ ) reconhecimento de um alcance bastante limitado na política de repressão às drogas, atingindo basicamente o tráfico de varejo e o porte para uso; i) reconhecimento de enorme distanciamento entre teoria e prática na formação policial; j) a aproximação da associação entre consumidores e policiais;

As análises das narrativas nos conduzem para a reflexão da importância de implicação do Poder Judiciário. Visto que, se de um lado, as práticas policiais denunciam como é demasiadamente forte a identificação feita entre criminalidade e negritude, de outro, temos que considerar que estas práticas, como postas, não são de responsabilidade exclusiva dos policiais ao decidirem executar seu tirocínio. Na verdade, há um ambiente social, institucional e, sobretudo, judicial, que consente e valida práticas e ações como as relatadas acima. A melhoria dos 
procedimentos policiais depende também de uma mudança no posicionamento de outras instâncias, sobretudo do Poder Judiciário.

Os dados apontam para um fato evidente, mas pouco debatido: $O$ policial tem em mira a valorização de seu trabalho pela prisão e condenação dos suspeitos. Logo pratica uma série de ações sabendo que o resultado será validado pelo Poder Judiciário. Poder Judiciário que, ao validar o resultado, é indiferente ao controle dos métodos adotados. Portanto, o Policial sabe que o reconhecimento de seu bom trabalho (número de prisões) não está submetido ao escrutínio de nenhum poder além do poder institucional de sua corporação.

Nesse modelo, todos sabem que o trabalho policial poderá sempre contar com Juízes e Tribunais responsáveis por adotar implicitamente as seguintes premissas: a) no espaço público e no espaço das periferias as abordagens (e humilhações) cotidianas não são inconstitucionais, desde que executadas contra grupos discriminados socialmente, pois servem para a garantia da ordem pública; b) as abordagens policiais não dependem de fundamentação concreta que seja prévia a sua execução desde que realizadas no espaço público ou no espaço da periferia, e contra grupos socialmente discriminados, bastando argumentos genéricos sobre a necessidade de segurança pública; c) a política de drogas quando produz efeitos, sobretudo o aumento dos padrões de violência institucional no espaço público e no espaço da periferia, desde que contra grupos socialmente discriminados, não é inconstitucional; d) compete ao cidadão, integrante das categorias anteriormente apontadas, custodiado ou violentamente abordado, interrogado para que confesse ou delate, mesmo fora de uma delegacia, a prova de que essa custódia ou abordagem foi violenta ou ilegal e de se viu forçado a violar seu direito ao silêncio para que a confissão ou delação seja considerada prova ilícita; e) não é possível reconhecer com base na experiência empírica, cotidiana e científica, que os padrões de violência institucional são inconstitucionais, portanto, não se pode impor nenhuma norma restritiva ao trabalho executado pela polícia; f) o problema da violência policial é excepcional e uma questão de educação, logo o aumentos dos programas de formação profissional resolverá essa violência eventual;

Infelizmente, o poder de fato da Polícia é um poder jurídico, pois autorizado pelo Poder Judiciário que necessitar rever sua política de validação da violência e do racismo institucionalizado. Perceber que as responsabilidades são compartilhadas, nos faz entender como a violência policial só existe quando um Judiciário que consente é também violento. A violência do Poder Judiciário é silenciosa e auto-imunizada pelo formalismo de nossa cultura jurídica. Entretanto, o rechaço das práticas policiais pelo Poder Judiciário permitiria reconhecer, em parte, o status de cidadão a esses jovens e recuperar a legitimidade, senão da Polícia, ao menos do próprio Poder Judiciário nesse debate. 


\title{
SUSPECTS? NARRATIVES AND EXPECTATIONS OF YOUNG BLACK MAN AND WOMEN AND MILITARY POLICE OFFICERS CONCERNING POLICE APPROACH AND RACIAL DISCRIMINATION IN BRASILIA, SALVADOR AND CURITIBA
}

\begin{abstract}
In the context of discussing the high homicide rates of young blacks, the article explores the dimension of racial violence practiced within security institutions and its effects on the targets of these institutions. The narratives, obtained through focus groups of military police officers and young blacks in three Brazilian cities (Brasilia, Salvador and Curitiba), are discussed to bring out the perceptions which guide the work of the first group and point to the members of the second group as suspects. Therefore, focusing on the actions which make up the drug policy, we will concentrate on reports to understand how patterns of prejudice are reproduced institutionally, especially the racial ones. The understanding of the statements given by police officers allows us to grasp how racial (in relation to blacks - black and brown) and social (relative to class) prejudices construct the suspicion reproduced in the approaches. At the same time, when we go through the narratives of young blacks we discover the effects of being this life always under suspicion. In the end, remarks will be made pointing up the need to judicialize police practices, which would allow us to acknowledge the citizen status of these young blacks partly and recover the legitimacy, if not by the police, at least by the Judiciary in this debate.
\end{abstract}

Keywords: Suspect; Police Officer; Young Blacks; Approach; Racism; Selectivity.

\section{REFERÊNCIAS BIBLIOGRÁFICAS}

ADORNO, Sérgio. Discriminação racial e justiça criminal. Novos Estudos, n. 43, nov. 1995.

AMAR, Paul. Táticas e termos da luta contra o racismo institucional nos setores de polícia e de segurança. In RAMOS, Silvia; MUSUMECI, Leonarda. Elemento Suspeito. Rio de Janeiro: Civilização Brasileira, 2005.

ANDRADE, Vera Regina Pereira de. A ilusão de segurança jurídica. Porto Alegre: Livraria do Advogado, 1997. 
BARATTA, Alessandro. Criminologia crítica e crítica do direito penal. RJ: Freitas Bastos, 2000.

BERTÚLIO, Dora Lúcia de Lima. Direito e relações raciais: uma introdução crítica ao racismo. Dissertação (Mestrado em Direito). Florianópolis: UFSC, 1989.

BROOKSHAW, D. Raça e Cor na Literatura Brasileira. Porto Alegre: Mercado Aberto, 1983.

DUARTE, E. C.P.; MURARO, M. ; LACERDA, M. ; DEUS GARCIA, Rafael de. Quem é o suspeito do crime de tráfico de drogas? Anotações sobre a dinâmica dos preconceitos raciais e sociais na definição das condutas de usuário e traficante pelos Policiais Militares nas Cidades de Brasília, Curitiba e Salvador. In: Isabel Seixas de Figueiredo; Gustavo Camilo Baptista e Cristiane do Socorro Loureiro Lima. (Org.). Pensando a Segurança Pública e Direitos Humanos: Temas Transversais. 1ed.Brasília: Ministério da Justiça (SENASP), 2014, v. 5, p. 81 120.

DUARTE, Evandro C. Piza. Criminologia e Racismo. Curitiba: Juruá, 2002.

FLAUSINA, Ana Luiza Pinheiro. Corpo negro caído no chão. RJ: Contraponto, 2008.

FORMIGA, G.S.F. A cor vigiada: uma crítica ao discurso racializado de prevenção ao crime. 112 f. Dissertação (Mestrado em Antropologia Social) - UnB; Brasília, DF, 2010.

GUIMARÃES, Antônio Sérgio. O insulto racial. Estudos afro-asiáticos. Dez. 2000, n. 38, p. 31-48.

IANNI, Octávio. Escravidão e racismo. SP: HUCITEC, 1988.

KARAM, Maria Lucia. "Guerra às drogas" e criminalização da pobreza. In: Zilio, Jacson. Bozza, Fábio (Org). Estudos críticos sobre sistema penal. Curitiba: LedZé, 2012.

LIMA, Roberto Kant de. Cultura jurídica e práticas políticas: A tradição inquisitorial. Revista Brasileira de Ciências Sociais, RJ,v. 4, n. 10, p. 65-83, jun. 1989.

MACHADO, E.P.; NORONHA, C.V. A Polícia dos Pobres. Sociologias, v. 4, n. 7, p. 188-221, jan/jun 2002. 
MATTOS, M.J.S. Reconhecimento, Identidade e Trabalho sujo na PMDF. Dissertação de Mestrado em Sociologia UnB. Brasília: 2012.

MOURA, Clóvis. Dialética radical do negro no Brasil. SP: Anita, 1994.

PORTO, Maria Stela Grossi; Crenças, valores e representações sociais da violência. Sociologias, ano 8, n.16, p.250-273, jul/dez 2006.

PRANDO, Camila Cardoso de Mello. A Contribuição do Discurso Criminológico Latino-Americano para a Compreensão do Controle Punitivo Moderno. Belo Horizonte. Veredas do Direito, Julho-Dezembro de 2006, v.3, n.6, p.77-93.

RAMOS, Silvia; MUSUMECI, Leonarda. Elemento Suspeito. RJ: Record, 2005.

SILVA, Gilvan Gomes Da. A Lógica da PMDF na Construção do Suspeito. Dissertação de Mestrado em Sociologia UnB. Brasília, DF, 2009.

SILVA, Jorge da. Violência e racismo no Rio de Janeiro. Niterói: EDUFF, 1998.

WACQUANT, Loïc. Punir os Pobres: RJ: Freitas Bastos, 2001.

ZAFFARONI, Eugenio Raúl. Em busca das penas perdidas: a perda de legitimidade do sistema penal. Rio de Janeiro: Revan, 1991

ZAFFARONI, Eugenio Raul. O Inimigo no Direito Penal. RJ: Revan, 2007.

Trabalho enviado em 24 de maio de 2018

Aceito em 17 de setembro de 2018 